\title{
THE SOCIAL AND FINANCIAL EFFICIENCY OF MICROFINANCE INSTITUTIONS: THE CASE OF BOSNIA AND HERZEGOVINA
}

Velid Efendic, Nejra Hadziahmetovic

\section{Abstract}

This paper investigates the financial and social efficiency of microfinance institutions ("MFIs") in Bosnia and Herzegovina, as well as the effects of the latest crisis on these "two-dimensional" efficiencies. Specifically, we analyze the efficiency of MFIs in Bosnia and Herzegovina (BiH) as a good case of a European, post-war country in transition with a developed micro-financial sector. The efficiency analysis relies on secondary data collected and investigated through Data Envelopment Analysis (DEA). The study covers data for the period commencing in 2008 and ending in 2015. In our empirical investigation, we find a suboptimal level of both financial and social efficiency among MFIs in BiH. However, financial efficiency is significantly higher than social efficiency, while small-sized MFIs over perform larger ones in both the financial and social dimensions. As a result of the crisis, MFIs recorded a declining trend in efficiency up to 2010, after which they began to show signs of slow recovery. However, our results suggest that MFIs prioritized financial over social goals in recovery period following the crisis.

Keywords: Efficiency, Microfinance institutions, Bosnia and Herzegovina

JEL classification: $C 14, G 29, L 31$

\section{INTRODUCTION}

Microfinance tends to focus on serving low-income populations and as such has been promoted as a powerful solution in the fight against global poverty (AnneWelle-Strand et. al. 2010; Cull, DemirgucKuntand Jonathan 2009). We are currently witnessing a global debate over whether MFIs adhere to their initial socio-economic mission or are shifting towards prioritizing the achievement of their financial goals. (Widiarto and Emrouznejad 2015). It remains important that, in order to reach higher efficiency, MFIs should achieve successful outputs in both dimensions: social impact and financial sustainability. In the last few decades, microfinance has evolved on a global level from microcredit and micro-loans to borrowers previously without access to credit into complex microfinance (Ernst\&Young 2014).

Although MFIs share many commonalities with traditional banks, such as the approval of loans, the charging of interest rates, collection of debts and in certain cases the collection of deposits, they still tend

\section{Velid Efendic, PhD}

School of Economics and Business

University of Sarajevo, Bosnia and Herzegovina

E-mail: velid.efendic@efsa.unsa.ba

Nejra Hadziahmetovic, MA

Team assistant at World Bank Office in Sarajevo

E-mail: nhadziahmetovic@worldbank.org 
to operate in a different manner. The main difference, when compared to banks, lies in a MFI's double bottom line objective: social outreach and financial sustainability (Gutiérrez-Nieto et al. 2007). There are numerous studies that focus on banks, while the literature on MFIs is very limited (Widiarto and Emrouznejad 2015). Huge gaps can be identified, especially if we consider the role of MFIs in low-income countries. The main reason for these research gaps is the lack of available and standardized data (Widiarto and Emrouznejad 2015). This is a significant issue, since improvements in transparency levels would result in better fund allocation and would also provide benefits to donors and investors (Tucker 2011).

When it comes to measuring the efficiency of MFIs, we refer to the manner in which MFIs allocate and utilize their resources, such as assets and employees, in order to produce outputs measured in terms of their loan portfolio and poverty outreach (Bassem 2008). When measuring efficiency, both parametric and nonparametric methods can be employed. In the last few decades, non-parametric methods have been used extensively. According to Emrouznejad and Yang (2017), until 2016, there were 10,300 recorded studies that utilized non-parametric DEA analysis in their efficiency estimations.

However, traditional financial indicators are not sufficient when assessing microfinance performance, since, due to their special dual nature, sustainability is not necessarily limited to profitability but rather to the MFIs' ability to operate in the long run (Widiarto and Emrouznejad 2015). Using the traditional financial ratios in order to assess the efficiency of MFIs can be ambiguous, since they can succeed in one aspect but fail in others (Bogetoft and Otto 2010). When analyzing MFI efficiency, a modern efficiency approach is needed, one that is capable of being applied to multipleinputs and multiple-outputs, as DEA does (Widiarto and Emrouznejad 2015).

The motivation for conducting this research is primarily to fill an identified research gap in this area. To the best of our knowledge, this is the first study investigating the social efficiency of MFIs in BiH using a non-parametric method. We identify $\mathrm{BiH}$ as a good case for the efficiency analysis of MFIs. MFIs from BiH are considered among the most successful on an international scale (Mix and AMFI 2009), which makes $\mathrm{BiH}$ a good example for testing the technical efficiency of MFIs. Secondly, this is the first study to explore "twodimensional efficiency" in $\mathrm{BiH}$, namely both financial and social efficiency. One study assessing MFIs' financial efficiency was conducted by Efendic and Hadzic (2017); however, the study does not include an analysis of both dimensions of efficiency.
The social dimension is especially important, since the microfinance sector in $\mathrm{BiH}$ began to develop after the war in the nineties as a tool in the fight against poverty and in post-conflict reconciliation (AnneWelleStrand et al. 2010). The MFI sector plays an important role in financial inclusion in $\mathrm{BiH}$. Considering how much time has passed since the war (1992-1995), it is important to determine whether MFIs in $\mathrm{BiH}$ are still concerned with their social role. In addition, our aim is to analyze levels of efficiency and to explore the differences among different sized MFIs, as well as the effect of the financial crisis on MFI efficiency. The recent financial crisis affected the European financial system and MFI operations with it. There is no study that explores the effect of the crisis on MFIs' financial and social efficiency in any of the European countries, to our knowledge.

The paper is organized as follows. Section 2 provides details on the financial and social dimensions and efficiency of MFIs. Microfinance in BiH is covered in Section 3, where the development of the sector and a short overview of the market in two $\mathrm{BiH}$ entities, the Federation of $\mathrm{BiH}$ and Republika Srpska, is briefly presented. Methodology and data are covered in Section 4 , followed by a discussion of the empirical results in Section 5. The paper ends with conclusions and recommendations for further research.

\section{THE "TWO DIMENSIONAL" EFFICIENCY OF MICROFINANCE INSTITUTIONS}

Economic efficiency is rather a broad term that implies a state in an economy whereby resources are allocated in such a manner that their purpose, for which they are being used, is maximized, while waste and inefficiencies are minimized. Accordingly, measuring institution's economic efficiency represents one of the primary challenges of micro-economic analysis (Efendic 2014).

One of the most famous and most commonly used definitions of economic efficiency is "Pareto optimality," provided by Vilfredo Pareto (Cooper et al. 2006). This approach is further extended and exploited in DEA as the "Pareto-Koopmans" definition of efficiency (Cooper et al. 2006). Accordingly, measuring efficiency became an important activity, as organizations began to focus on improvements in their productivity (Cook and Seiford 2009). With its ability to cover different aspects of microfinance institutions, efficiency has been proposed as a measurement criterion of MFIs performance (Balkenhol 2007).

Because of MFIs' dual nature, serving both social and financial goals, there is a debate among those 
whose focus is on the financial side, and those whose focus is on social aspects. Institutionalists focus on the financial aspects and are concerned with selfsufficiency and sustainability (Serrano-Cinca et al. 2009). On the other hand, welfareists claim that MFIs have to help the poor first, while profitability should be a secondary concern (Serrano-Cinca, et al. 2009). Accordingly, there is a belief that MFIs can achieve sustainability without achieving financial self-sufficiency (Morduch 2000). In addition, Morduch also claims that the discussion on microcredit performance almost completely ignores financial matters. The truth is that even though the primary goal of MFIs is to enable access to funds for low-income populations, they will not be able to achieve that goal without sustainable profitability. It can be concluded that MFIs must be efficient in both aspects in order to achieve "two-dimensional efficiency".

MFI efficiency is rarely assessed and analyzed, and when it is, the focus is usually on the financial aspect. When discussing social performance, the Yaron (1994) framework is widely accepted as a standard way of assessing MFIs. The framework is based on outreach and sustainability concepts. Outreach accounts for the number of clients that are being served and the quality of products offered to them. Alternatively, sustainability implies that the institution is generating income levels that are at least enough to cover the opportunity costs (Chaves and Gonzalez 1996). However, when it comes to measuring the social Double-Bottom line, there is no universal standard present (Zeller et al. 2006). Even though literature on the two-dimensional efficiency of MFIs is quite limited, there are a few influential studies. Wijesiri et al. (2015) in their paper examine the efficiency of $36 \mathrm{MFIs}$ in Sri Lanka with two different DEA models in order to obtain scores for financial and social inefficiency. Conversely, a significant number of the observed MFIs are inefficient in both dimensions. This finding leads to the conclusion that MFIs that are inefficient in both dimensions, or efficient in only one, should work on solving their weaknesses and restructure their policy choices (Wijesiri et al. 2015).

Widiarto and Emrouznejad (2015) focus on the comparison of the DEA efficiencies of Islamic and conventional MFIs in terms of their social and financial efficiency. The study covers three different regions: the Middle East and North Africa (MENA), East Asia and the Pacific (EAP) and South Asia (SA) for the period from 2009 to 2010. Its results showed that MFIs in the EAP region perform quite impressively in their overall and financial efficiency, while their social efficiency is mediocre on average (Widiarto and Emrouznejad 2015). The main source of inefficiency, including overall, financial and social, is technical inefficiency. When it comes to the question of whether financial and social efficiency are mutually exclusive, Lebovics et al. (2016) found in 28 Vietnamese MFIs for the year 2011 that there was no correlation between those two types of efficiencies, meaning that there is no tradeoff between them. They stress that where financial efficiency is concerned, learning effects and cost-efficiency seem to be crucial, whereas for social efficiency the quality of staff and the quality of leadership of the top managers appears to be of the most importance.

The relationship between financial and social efficiency measured by DEA was also the research focus of Serrano-Cinca et al. (2009). Of the 89 MFIs included in their international sample, only 13 show a higher level of social efficiency in comparison to financial efficiency. The conclusion is that when faced with a choice between social and financial efficiency, MFls choose financial performance in order to be able to continue with their social aims.

Finally, social and financial efficiency is still at an early phase of research development and only a few studies have been conducted in this field. In addition, there are not many studies on MFIs efficiency in European countries. To the best of our knowledge, the social and financial efficiency of MFIs in Bosnia and Herzegovina were not explored in any of the previous studies. The aim of this study is to fill the identified gap in the literature.

\section{MICROFINANCE IN BOSNIA AND HERZEGOVINA}

$\mathrm{BiH}$ is a transitional and developing country and is composed of two autonomous entities, the Republika Srpska ("RS") and the Federation of $\mathrm{BiH}$ ("FBiH"). Accordingly, the supervision of MFIs is at the entity and not the state level. However, MFIs in $\mathrm{BiH}$ were confronted with an enormous challenge when they first began providing loans (Berryman and Pytkowska 2014).

After the war in the nineties, microfinance in $\mathrm{BiH}$ played a dual role: to fight against poverty and as a tool for post-conflict reconciliation (AnneWelleStrand, et al. 2010). After the war, unemployment rose to a level close to $85 \%$, (Berryman and Pytkowska 2014). A large number of the MFIs operating today in this area began to operate in 1997 (Berryman and Pytkowska 2014).

Support to MFIs was mainly provided by the World Bank and a number of other bilateral and multilateral donors via its funding of a so-called local initiative projects (LIP) (WB 2005). By $2009 \mathrm{BiH}$ was officially 
Figure 1: The Number of MFIs in $\mathrm{BiH}$

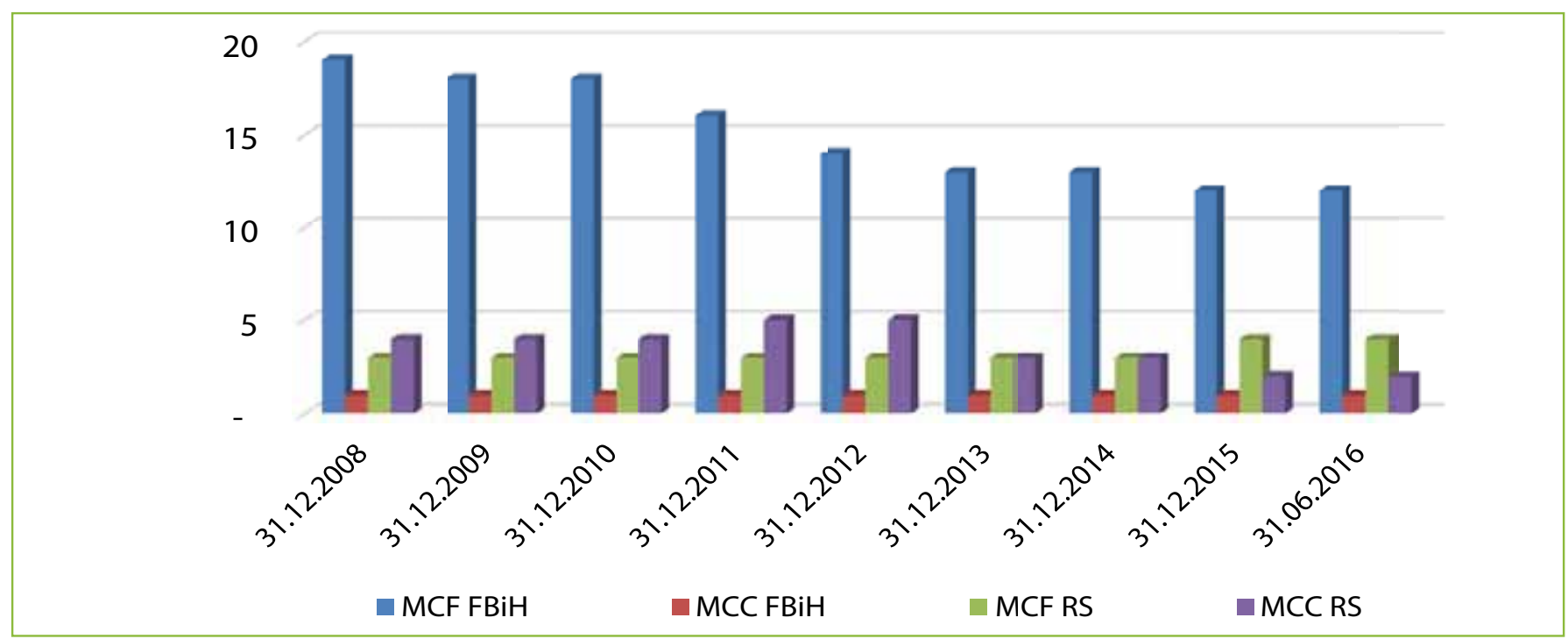

Source: Reports published by Banking Agencies in FBiH and RS; MCF refers to Microfinance foundations as non-profit MFIs. MCC refers to the micro-credit companies as for-profit MFIs 1

Table 1: Overview of the financial services sector in $\mathrm{BiH}$

\begin{tabular}{|c|c|c|c|c|c|c|c|c|}
\hline \multirow[b]{2}{*}{$\begin{array}{l}\text { Segment of the financial services } \\
\text { sector (financial institutions) }\end{array}$} & \multicolumn{2}{|c|}{2012} & \multicolumn{2}{|c|}{2013} & \multicolumn{2}{|c|}{2014} & \multicolumn{2}{|c|}{$\begin{array}{l}\text { Assets growth } \\
\text { index }\end{array}$} \\
\hline & $\begin{array}{c}\text { Assets } \\
\text { (in BAM } \\
\mathrm{mln} \text { ) }\end{array}$ & $\begin{array}{l}\text { Share } \\
(\%)\end{array}$ & $\begin{array}{c}\text { Assets } \\
\text { (in BAM } \\
\text { mln) }\end{array}$ & $\begin{array}{l}\text { Share } \\
(\%)\end{array}$ & $\begin{array}{c}\text { Assets } \\
\text { (in BAM } \\
\mathrm{mln} \text { ) }\end{array}$ & $\begin{array}{l}\text { Share } \\
(\%)\end{array}$ & $13 / 12$ & $14 / 13$ \\
\hline Banks & 21,226 & 86.31 & 22,066 & 87.13 & 22,821 & 87.35 & 103.96 & $10 ., 42$ \\
\hline Investment funds & 795 & 3.23 & 761 & 3 & 790 & 3.02 & 95.72 & 103.81 \\
\hline Insurance and reinsurance companies & 1,174 & 5.27 & 1,232 & 4.86 & 1,356 & 5.19 & 104.94 & 110.06 \\
\hline Microcredit organizations & 681 & 2.28 & 670 & 2.65 & 646 & 2.47 & 98.38 & 96.42 \\
\hline Leasing companies & 716 & 2.91 & 597 & 2.36 & 512 & 1.96 & 83.38 & 85.76 \\
\hline Total for sector & 24,592 & 100 & 25,326 & 100 & 26,125 & 100 & 102.98 & 103.15 \\
\hline
\end{tabular}

Source: FBA, BARS, FBiH Securities Commission, RS Securities Commission, FBiH Insurance Supervisory

classified as the world's second most microfinancesaturated country (Milford et al. 2012).

According to the latest reports from 2016 published by the Banking Agency of the FBiH, 12 MFIs held a license for business operations in $\mathrm{FBiH}$. Among those 12,11 are non-profit organizations and 1 of which is a for-profit organization (FBA 2016). When we focus on microfinance in RS, according to the latest report published by the Banking Agency of RS, 8 MFIs held a license for doing business. Of these $8 \mathrm{MFIs}, 5$ are registered as for-profit institutions and 3 are registered as non-profit organizations (ABRS 2016) (See Figure 1).

In 2014, the microfinance sector held less than 3\% of total assets of the financial system and its share has been declining since 2008, when its sector share was $4.7 \%$. The details of these changes are presented in Table 1.

Based on the data presented in Table 1, it can be concluded that banks dominate the market. Analysis of the trends in financial performance and efficiency indicators in the period from 2008 to 2015 shows that the microfinance sector in $\mathrm{BiH}$ recorded a significant decline in most of the indicators, which highly correlate with the drop in total assets as well as in loans received from external financiers (Efendic and Hadzic 2017).

In addition, it is important to mention that MFIs in $\mathrm{BiH}$ have received in the last 15 years significant recognition and have been awarded for their high level of transparency and financial reporting.

1 Based on the Law on Microcredit organizations ('Official Gazette of the $\mathrm{FBiH}^{\prime}$, No. 59/06) there are different capital requirements for Microcredit companies and Microcredit foundations: for a company $500,000 \mathrm{BAM}$, and for a foundation 50,000 BAM. Another major difference is in the maximum amount of credit that can be approved: for companies, this is 50,000 BAM, for foundations 10,000 BAM. 


\section{METHODOLOGY AND DATA}

Parametric frontiers and Data Envelopment Analysis are the two main methodological approaches in efficiency assessment. The second is a non-parametric method that show an exponential growth in its use in academic research over the last forty years (Emrouznejad and Yang 2017). In addition, it is one of the most recommended methods when assessing the efficiency of financial institutions, and according to Banker and Natarajan (2008, p. 49) DEA methods were shown to be better than one-stage and twostage parametric methods when estimating the individual productivity of institutions. In total there have been 10,300 DEA-related research articles published in different journals (Emrouznejad and Yang 2017). In comparison to parametric methods, DEA is based on a complex multi-input/output structure and deals with these issues in an effective and efficient way (Cooper et al. 2006).

The three other "frontier" parametric methods that are most commonly used are the "Stochastic Frontier Approach (SFA)" (Berger and Humphrey 1997), "Thick Frontier Approach (TFA)" (Berger and Humphrey 1997) and "Distributional Free Approach" (DFA) (Schmidt and Sickles 1984). The main characteristic of parametric methods is that they require prior formulation of the efficiency function and shape of the frontier.

For the purpose of our research we apply the DEA method as one of the most used and most popular non-parametric methods among researchers due to its objectivity based on the quantitative analysis of available data. In addition, DEA does not require an assumption of a functional form (Ramanathan 2003). Also, the DEA method is extensively used in analysis of banking efficiency in developing countries (Grigorian and Manole 2006), which is characteristic of $\mathrm{BiH}$ as well. Anayiotos et al. (2010, p. 250) choose the DEA method as appropriate for efficiency analysis since it is used in many analyses of bank efficiency and insurance companies; it is non-parametric method and therefore potentially inadequate assumptions regarding the error distribution are generally avoided; finally, the method separately analyzes the efficiency of each unit in relation to its reference, and in that way ensures the relative measure of efficiency for each of those units. In addition, DEA is an appropriate method for analysis of smaller sample sizes, with less data required and fewer assumptions to make (Evanoff and Israilevich 1991), and does not need a longer time series (Anayiotos et al. 2010). At the same time, the biggest disadvantage of this method is that it does not take into account measurement errors (Mester 1996). Also, statistical inferences are not possible with nonparametric methods, hence the DEA will account for the influence of different environmental objective factors as inefficiency (Evanoff and Israilevich 1991).

The DEA method is based on non-parametric linear programming efficiency analysis, which forms a linear production envelope or frontier on top of all of the data (Emrouznejad, et al. 2008). The decisionmaking units (DMU) that form the envelope and lie on the frontier are the best-practice units or benchmarks (Cooper et al. 2006), and accordingly, these DMUs are in DEA indices equal to " 1 ". Otherwise, all other DMUs are considered inefficient, with DEA indices in the range between " 0 " and " 1 " (Ramanathan 2003).

The two basic DEA models are the CCR model of Charnes et al. (1978) and the BCC model of Banker et al. (1984). CCR assesses technical efficiency under a Constant Return to scale (CRS) condition (Charnes et al. 1979). In the basic DEA model, there are two approaches that can be used, the input-oriented approach, which maximizes proportional input reduction while holding outputs constant, and the outputoriented approach, which alternatively maximizes proportional output increase while keeping inputs constant (Charnes et al. 1979).

\section{Input - oriented approach}

$$
\begin{aligned}
& \theta^{*}=\operatorname{Min} \theta \\
& \text { subject to } \\
& \sum_{j=1}^{n} x_{i j} \lambda_{j} \leq \theta^{*} x_{i 0} i=1,2, \ldots, m \text {; } \\
& \sum_{j=1}^{n} y_{r j} \lambda_{j} \geq y_{r 0} r=1,2, \ldots, s \text {; } \\
& \sum_{j=1}^{n} \lambda_{j}=1 \\
& \lambda_{j} \geq 0 j=1,2, \ldots, n \\
& \text { Where: } \\
& \boldsymbol{\theta}^{*} \text { is the optimal solution } \\
& \boldsymbol{x}_{\boldsymbol{i} j} \text { the inputs vector of DMUi } \\
& \boldsymbol{y}_{\boldsymbol{r} \boldsymbol{j}} \text { the outputs vector of DMUr } \\
& \sum_{j}^{n} \lambda_{j}=\mathbf{1} \text { the convexity constraint }
\end{aligned}
$$

The DEA original formulation with the assumption of Constant Return to Scale (CRS), means that institutions were analyzed as they operate on the most productive scale (Widiarto and Emrouznejad 2015). Considering that this is often not the case, Banker et al. (1984) introduced the constraint $\sum_{j}^{n} \lambda_{j}=1$ to represent 
the convexity constraint for $\lambda_{j}$ in Variable Return to Scale (VRS) condition, so that an institution will be compared to a similarly-sized institution that has a similar return to scale (Widiarto and Emrouznejad 2015). Hence, the scale efficiency (SCALE) was found to be the relative difference between CRS and VRS (CRS/ VRS) technical efficiency scores (Coelli et al. 2005). In our analysis, we employed a VRS input-oriented, grand-frontier DEA model with pooled data. Although we considered using the output oriented method as well, we finally decided for input orientation due to the aim of evaluating the efficiency of management of MFIs in managing inputs to produce desired social and financial outputs.

When assessing MFI efficiency there are two approaches that can be used: the production and intermediation approaches (Berger and Humphrey 1997). The main difference between these two is that the production approach observes MFIs as a production unit that uses inputs such as labor to produce outputs such as loans and other financial services (Haq et al. 2010). Under the intermediation approach, MFIs are treated as DMUs that use inputs of deposits from surplus units to deliver outputs (loans and other financial services) to deficit units (Kipesha 2012).

MFIs in $\mathrm{BiH}$, according to its local laws, are not allowed to collect deposits, due to that fact in our paper we use a production approach, as is done in many other studies in which the MFIs analyzed are not deposit-taking institutions (e.g. Kipesha 2012; Haq et al. 2010; Gutiérrez-Nieto et al. 2009; Hassan and Sanchez 2009; Sedzro and Keita 2009; Fluckiger and Vassiliev 2007; Gutiérrez-Nieto et al. 2007).

\subsection{Selection of inputs and outputs}

Specification of the inputs and outputs is crucial step when analyzing a financial institution (Serrano-Cinca et al. 2009). Berger and Humphrey (1997) suggest that one could assess efficiency under a variety of different output/input specifications, and see how the calculated efficiencies change as the specification changes. Still, there is no clear guideline on how to chose among a variety of specifications (Serrano-Cinca et al. 2009). Researchers may be tempted to add as many inputs and outputs as they find important or relevant for the purpose of their analysis, but problems arise if some of them are highly correlated (Jenkins and Anderson 2003). Another issue is that as we increase number of inputs and outputs in the DEA model, the number of DMUs with $100 \%$ efficiency also increases, and by adding an irrelevant variable in the model the result obtained could also change (Chaparro et al. 1999). However, after conducting a review of the available literature we decided to develop one main model specification and one test model specification. With respect to the availability of data in our sample, we considered all of the possible variables that are used in other studies and made a final list of inputs and outputs that are relevant for our research and in line with microeconomic theory. The inputs and outputs that we used for the purposes of our analysis are summarized in Table 2.

This study utilizes the data for 15 MFIs for the period from 2008 to 2015, with four registered in the $\mathrm{RS}$ and rest in FBiH. Data was obtained from several sources: official reports published by the Federal Banking Agency and Banking Agency of Republika Srpska, the MIX Market Database, Financial reports available on the MFIs' websites and Reports published by AMFI BiH (the Association of MFIs in $\mathrm{BiH}$ ) for the period from 2008 to 2013. All monetary data are presented in BAM (Bosnian Convertible Mark, the official currency in $\mathrm{BiH}$ ). The inputs used in the main model are the number of employees and total assets. Following microeconomic theory, labor and capital are the primary factors in the production process (Parkin 2012, p. 4). Accordingly, as a first "labor" input in our model we consider the number of employees. This input is extensively used in most of the previous efficiency analysis models (among others: Kipesha 2012; Haq et

Table 2: DEA Input / Output Variables

\begin{tabular}{|c|c|c|}
\hline & Inputs & Outputs \\
\hline \multicolumn{3}{|c|}{ Efficiency Models } \\
\hline Financial Efficiency & $\begin{array}{l}\text { - Number of Employees } \\
\text { - Total assets }\end{array}$ & $\begin{array}{l}\text { - Financial Revenue } \\
\text { - Gross Loan Portfolio }\end{array}$ \\
\hline Social Efficiency & $\begin{array}{l}\text { - Number of Employees } \\
\text { - Total assets }\end{array}$ & - Number of Active Borrowers \\
\hline \multicolumn{3}{|c|}{ Test model } \\
\hline Financial Efficiency & $\begin{array}{l}\text { - Number of Employees } \\
\text { - Total assets }\end{array}$ & - Gross Loan Portfolio \\
\hline
\end{tabular}


al. 2010; Sedzro and Keita 2009; Hassan and Sanchez 2009; Bassem 2008). The number of employees in our model reflects efficiency in managing human resources, which means that a MFI that produces a given level of outputs with fewer employees is considered a more efficient institution. As a second "capital" input we consider total assets to represent the capital for a production approach. Total assets as a category that shows little variability in the short term has widely been used as an input variable in many studies as well (among others: Widiarto and Emrouznjead 2015; Wijesiri et al. 2015; Tahir 2013; Kipesha 2012; Gutiérrez-Nieto et al. 2009; Hassan and Sanchez 2009; Bassem 2008; Gutiérrez-Nieto et al. 2007). In our model specification, this variable reflects the quality of managing the assets within one MFI. Accordingly, an MFI with a lower level of assets used in order to produce a given level of outputs is more efficient. The higher quality of management over the assets will result in more units of the outputs per unit of the assets. For outputs for financial efficiency we decided to use gross loan portfolio and financial revenue. Gross loan portfolio reflects the MFIs' role in financial intermediation and reflects the main output in the production process of the financial institution. This variable has been used as an output in previous studies as well (among others: Kipesha 2012; Hassan et al. 2012; and Gutiérrez-Nieto et al. 2009). Accordingly, considering the inputs used in the model, a higher level of loans provided/produced within one MFI reflects its higher efficiency in core business. The second output in our model, "financial revenue," is extensively used as an output in the production approach and as a proxy for sustainability. As an output in DEA, it is used in several previous studies as well (among others: Gutiérrez-Nieto et al. 2009 and Hassan and Sanchez 2009). It represents the performance of the institution in producing loans with a different level of quality. Accordingly, MFIs which in utilizing their inputs cannot collect enough revenue will not be able to operate and to achieve sustainability in the long run, no matter the level of loans provided.

However, the analysis of financial efficiency is more common, and thus it is easier to decide on inputs and outputs that will reflect MFI performance. This is not the case when focusing on the social dimension, which is rarely assessed and harder to measure (Serrano-Cinca et al. 2009). For the social efficiency model, we use the model specification with the same inputs as the main model of financial efficiency, and with the number of active borrowers as the single output. As the number of individuals that MFIs reach increases, MFIs are more efficient in fulfilling their founding mission of helping the unbanked population. More borrowers mean more of the unbanked population served. As such, it serves as a measure of MFI outreach and has been used in previous studies as well (among others: Widiarto and Emrouznejad 2015 and Tahir 2013). Definitions and references for variables used are provided in Appendix 1.

Considering the fact that we still do not have neither a consensus on the theory of banking firms, nor on the "explicit definition and measurement of banks' inputs and outputs" (Casu and Molyneux 2003, p. 1869), which is applicable to micro-finance institutions as a kind of banking firms, we do not have a consensus on the list of variables that reflect the "production" process and production function of these institutions. In line with this, we made an alternative model of DEA to check the stability of our results. Accordingly, considering the sensitivity of DEA on the selection of variables and number of variables (Fanchon 2003), to escape possible misspecifications we defined a test model with the same number of variables for financial efficiency as that of the social efficiency model (two inputs and one output). Accordingly, in the test model for financial efficiency we have decided to use the same two inputs as in the main model (number of employees and total assets) and a single output (Gross loans portfolio).

In the Table 3, descriptive statistics for the input and output data used are provided.

It is important to emphasize that in DEA analysis we only included non-zero, non-negative data and excluded MFIs that had less than two observations.

Table 3: Descriptive statistics -DEA inputs/outputs

\begin{tabular}{|l|l|l|r|r|r|r|}
\hline & Units & N & Minimum & Maximum & Mean & Std. Deviation \\
\hline Groloan & BAM `000 & 88 & 1402 & 228088 & 58101.89 & 57526.19 \\
\hline Finrev & BAM `000 & 88 & 134 & 69513 & 13699.83 & 13161.693 \\
\hline Noborow & Numeric & 88 & 886 & 65866 & 22511.61 & 19386.43 \\
\hline Noemploy & Numeric & 88 & 8 & 338 & 152.31 & 105.46 \\
\hline Totass & BAM ‘000 & 88 & 1532 & 251173 & 69343.42 & 67767.49 \\
\hline Valid N (listwise) & & 88 & & & & \\
\hline
\end{tabular}


Finally, we started with total a number of 119 observations, but due to the missing data we ended up with a total number of 88 observations (12 from RS MFIs and the rest for those in $\mathrm{FBiH}$ ). Following previous studies (Widiarto and Emrouznejad 2015), we conducted the correlation analysis on the selected inputs and outputs variables and found a high level of correlation between them. The high correlation between the selected variables is expected due to their structure and nature (items from the balance sheets and income statements of the MFI). However, we kept these variables since they are important in efficiency analysis of MFls (Widiarto and Emrouznejad, 2015) and also are used in many other studies (see Appendix 1). Following the explanation given by Widiarto and Emrouznejad (2015, p. 15), since the high correlations identified "do not necessarily imply causal relationship," we consider the DEA model appropriate and the results that it yields reliable. However, the same does not apply to the parametric efficiency measurement since the "multi-co-linearity problem makes beta coefficients for correlated independent variables unreliable" (Widiarto and Emrouznejad, p. 15). Finally, with respect to the given arguments we decided to choose DEA as a method for an efficiency analysis of MFIs in Bosnia and Herzegovina.

\section{EMPIRICAL RESULTS}

DEA efficiencies were calculated for each MFI with a VRS approach on grand-frontier for the period from 2008 to 2015 . The results imply that the majority of MFIs throughout the analyzed period have a higher level of financial than social efficiency. On average, DEA scores for both financial and social efficiency are suboptimal, 0.87 and 0.59 respectively. The results are summarized in the Table 4:
The given results "FVRSTE" and "SVRSTE" are our main model's VRS results for financial and social efficiency, respectively. In addition to these results, "FVRSTE2", which are provided in Appendix 4, represent the test model for financial VRS technical efficiency. However, the results from the given test model have a strong correlation with those of the main model (see Appendix 3). In all models we are focusing on the VRS results and discuss the results only for the main models ("FVRSTE" and "SVRSTE"). When analyzing the given results, we can see that they consistently lead to a common conclusion: MFls have a higher level of financial than social efficiency. Our test model shows almost identical results to the main model (see Appendix 4). The DEA score for financial efficiency is at the 0.87 level, and while the score for social efficiency is at the 0.59 level. Accordingly, efficiency overall is found to be rather low, especially with regard to the social dimension. When it comes to "FVRSTE", $87 \%$ is a signal of technical inefficiencies, with a potential of $13 \%$ for improvements. The study reveals even lower social efficiency, which is found at the level of $59 \%$, and which suggests that the potential for social efficiency improvements is $41 \%$. The given results reveal that MFIs are wasting their resources and there is significant potential to improve their technical efficiencies. This led us to the conclusion that MFIs in $\mathrm{BiH}$ use too much labor (employees) and capital (assets) for the level of their outputs. In addition, the similar results for CRSTE and VRSTE financial and social efficiency confirm that the scale of the operation is not the issue, since their scale efficiency is estimated at a level close to optimal. Finally, we can conclude that MFIs in $\mathrm{BiH}$ should reconsider business policies and their operations, and put additional focus on reaching a larger number of clients. In Table 5 return to scale efficiencies are presented for both dimensions.

Table 4: Summary statistics for the pooled DEA local grand-frontier (one frontier for all years)

\begin{tabular}{|l|c|c|c|c|c|}
\hline \multicolumn{7}{|c|}{ Variable } & Obs & Mean & Std. Dev. & Min \\
\hline \multicolumn{5}{|c|}{ Financial efficiency } \\
\hline FCRSTE & 88 & 0.86 & 0.08 & 0.59 & 1 \\
\hline FVRSTE & 88 & 0.87 & 0.09 & 0.60 & 1 \\
\hline FSCALE & 88 & 0.98 & 0.02 & 0.87 \\
\hline \multicolumn{5}{|c|}{ Social efficiency } \\
\hline SCRSTE & 88 & 0.55 & 0.15 & 0.37 & 1 \\
\hline SVRSTE & 88 & 0.59 & 0.18 & 0.39 \\
\hline SSCALE & 88 & 0.96 & 0.06 & 0.67 \\
\hline $\begin{array}{l}\text { List of } \\
\text { abbreviations: }\end{array}$ & $\begin{array}{l}\text { CRSTE- constant return to scale technical efficiency (TE); VRSTE - variable return to scale TE, SCALE - } \\
\text { Scale efficiency; F - stands for financial, S - stands for social dimension }\end{array}$ \\
\hline
\end{tabular}


Table 5: Summary statistics for the pooled DEA local grand-frontier (one frontier for all years) - return to scale efficiencies

\begin{tabular}{|l|l|c|c|c|c|}
\hline \multicolumn{2}{|l|}{ Financial efficiency } & Frequency & Percent & Valid Percent & Cumulative Percent \\
\hline \multirow{4}{*}{ Valid } & Optimal & 14 & 15.9 & 15.9 & 15.9 \\
\cline { 2 - 6 } & Drs & 57 & 64.8 & 64.8 & 80.7 \\
\cline { 2 - 6 } & Irs & 17 & 19.3 & 19.3 & 100.0 \\
\cline { 2 - 6 } & Total & 88 & 100.0 & 100.0 & Cumulative Percent \\
\hline \multirow{3}{*}{ Social efficiency } & Orequency & 4 & Percent & 4.5 & 4.5 \\
\hline \multirow{4}{*}{ Valid } & Optimal & 51 & 58.0 & 58.0 & 62.5 \\
\cline { 2 - 6 } & Drs & 33 & 37.5 & 37.5 & 100.0 \\
\cline { 2 - 6 } & Irs & 88 & 100.0 & 100.0 & \\
\cline { 2 - 6 } & Total & \multicolumn{2}{l}{} &
\end{tabular}

When it comes to the return to scale analysis, 14 units are considered benchmarks for financial efficiency analysis, which means that they have an efficiency equal to 1 or they create the efficiency frontier. However, 57 units or $64.7 \%$ have decreasing returns to scale, suggesting that they are exhausting their economies of scale. In addition, 17 units or $19.3 \%$ have increasing returns to scale, which means that unused capacities in the scale of their operations are present. When analyzing social efficiency, 4 units are considered benchmarks. Finally, 51 unites or $58 \%$ showed decreasing returns to scale, while 33 or $38 \%$ showed increasing returns to scale.

\subsection{Social vs. financial efficiency}

When it comes to the differences between financial and social efficiency, even though the primary mission of MFIs should be to make a social contribution, they cannot operate in the long run without financial sustainability. To explore the relationship between the financial and social efficiency of MFIs in BiH, Spearman's Rho Rank-Order correlation coefficients of DEA scores are calculated. According to the results of Spearman's correlation (Appendix 3), the social and financial efficiency of MFls in BiH have a significant positive correlation, which suggests that MFIs with higher financial efficiency also have higher social efficiency.

The institutional geographic position is also considered a relevant factor for MFI efficiency (GutiérrezNieto et al. 2009). Hence, we conducted an analysis of the differences between efficiency levels of MFIs operating in $\mathrm{FBiH}$ and those operating in the RS. As previously mentioned, our sample includes four MFIs from the RS, with the rest from $\mathrm{FBiH}$. The results for joint grand-frontier on pooled data (one frontier for all MFIs, in all years for both entities) are presented in Table 6.

According to the DEA scores from the main model, MFls operating in the RS have a slightly higher level of financial efficiency comparing to MFIs operating in $\mathrm{FBiH}(0.91$ vs. 0.87$)$ but on the other side, significantly

Table 6: Differences in DEA scores between entities (main model) 2

\begin{tabular}{|c|c|c|c|c|c|}
\hline \multicolumn{6}{|c|}{ Federation of Bosnia and Herzegovina (FBiH) } \\
\hline & $\mathrm{N}$ & Mean & Std. Deviation & Minimum & Maximum \\
\hline \multicolumn{6}{|c|}{ Financial efficiency } \\
\hline FCRSTE & 76 & 0.85 & 0.08 & 0.59 & 1.00 \\
\hline FVRSTE & 76 & 0.87 & 0.09 & 0.60 & 1.00 \\
\hline FSCALE & 76 & 0.98 & 0.02 & 0.87 & 1.00 \\
\hline \multicolumn{6}{|c|}{ Social efficiency } \\
\hline SCRSTE & 76 & 0.57 & 0.16 & 0.37 & 1.00 \\
\hline SVRSTE & 76 & 0.60 & 0.19 & 0.39 & 1.00 \\
\hline SSCALE & 76 & 0.96 & 0.07 & 0.67 & 1.00 \\
\hline $\begin{array}{l}\text { Valid N } \\
\text { (Listwise) }\end{array}$ & 76 & & & & \\
\hline \multicolumn{6}{|c|}{ Republika Srpska (RS) } \\
\hline \multicolumn{6}{|c|}{ Financial efficiency } \\
\hline FCRSTE & 12 & 0.89 & 0.07 & 0.81 & 1.00 \\
\hline FVRSTE & 12 & 0.91 & 0.08 & 0.81 & 1.00 \\
\hline FSCALE & 12 & 0.98 & 0.02 & 0.94 & 1.00 \\
\hline \multicolumn{6}{|c|}{ Social efficiency } \\
\hline SCRSTE & 12 & 0.46 & 0.06 & 0.38 & 0.60 \\
\hline SVRSTE & 12 & 0.48 & 0.05 & 0.43 & 0.60 \\
\hline SSCALE & 12 & 0.96 & 0.05 & 0.87 & 1.00 \\
\hline $\begin{array}{l}\text { Valid N } \\
\text { (listwise) }\end{array}$ & 12 & & & & \\
\hline
\end{tabular}

2 More detailed results are available by request from the corresponding author Velid dr. Efendic: velid.efendic@efsa.unsa.ba 
lower level of social efficiency ( 0.48 vs. 0.60$)$. The results show that MFIs in FBiH are socially more sensitive compared to MFIs in the RS, where the difference between the financial and social DEA scores is larger. For the efficiency comparison between $\mathrm{FBiH}$ and RS MFIs within the analyzed period, a Mann-Whitney rank sum test is used. This test is a non-parametric (distributionfree) test for testing an independent group with the aim of identifying whether the scores from one entity of $\mathrm{BiH}$ are ranked significantly higher than from the other. The Mann-Whitney rank sum test uses the ranks of the data, which means that the efficiency score is considered a test variable and the origin of the MFI is considered a group variable. Finally, according to the results from the Mann-Whitney test, there is a significant difference between the financial and social efficiency of MFIs in FBiH and the RS.

Table 7: Results of the Mann Whitney Test to compare differences in efficiency of MFIs from $\mathrm{FBiH}$ and $\mathrm{RS}$

\begin{tabular}{|l|l|c|c|c|}
\hline \multicolumn{5}{|c|}{ Ranks } \\
\hline $\begin{array}{l}\text { Mann-Whitney } \\
\text { Test }\end{array}$ & entity & $\mathrm{N}$ & $\begin{array}{c}\text { Mean } \\
\text { Rank }\end{array}$ & $\begin{array}{c}\text { Sum of } \\
\text { Ranks }\end{array}$ \\
\hline \multirow{2}{*}{$\begin{array}{l}\text { Financial effi- } \\
\text { ciency (FVRSTE) }\end{array}$} & RS & 12 & 52.58 & 631.00 \\
\cline { 2 - 5 } & FBiH & 76 & 43.22 & 3285.00 \\
\hline \multirow{2}{*}{$\begin{array}{l}\text { Social efficiency } \\
\text { (SVRSTE) }\end{array}$} & Total & 88 & & \\
\cline { 2 - 5 } & FB & 12 & 29.71 & 356.50 \\
\cline { 2 - 5 } & Total & 76 & 46.84 & 3559.50 \\
\hline
\end{tabular}

The results of the Mann-Whitney test reveal that there is a significant difference in efficiency due to the MFIs entity location. The same applies for both financial and social efficiency. Following the results (see Table 7 and Table 8), we can conclude that MFIs from the RS have statistically significant lower social efficiency compared to MFIs in $\mathrm{FBiH}$.

Table 8: Test statistics of the results of the Mann - Whitney Test to compare differences in efficiency of MFIs from $\mathrm{FBiH}$ and RS

\begin{tabular}{|l|c|c|}
\hline \multicolumn{3}{|c|}{ Test Statistics $^{\mathrm{a}}$} \\
\hline & $\begin{array}{c}\text { Financial efficiency } \\
\text { (FVRSTE) }\end{array}$ & $\begin{array}{c}\text { Social efficiency } \\
\text { (SVRSTE) }\end{array}$ \\
\hline Mann-Whitney U & 359.000 & 278.500 \\
\hline Z & -1.181 & -2.159 \\
\hline Asymp. Sig.(2-tailed) & .238 & .031 \\
\hline
\end{tabular}

In addition, we assessed differences in MFI efficiency based on the size of their assets. Generally speaking, the size of MFIs is important in efficiency analysis. Differently-sized institutions have different economies of scale, which means that their efficiency could be significantly different (Efendić and Hadžić 2017). Bassem (2008) assessed in his study the DEA efficiency of $35 \mathrm{MFIs}$ in the Mediterranean zone during the period between 2004 and 2005, and found that the size of the MFI has a negative effect on their efficiency. For

Figure 2: DEA scores in relation to total assets (main Model)

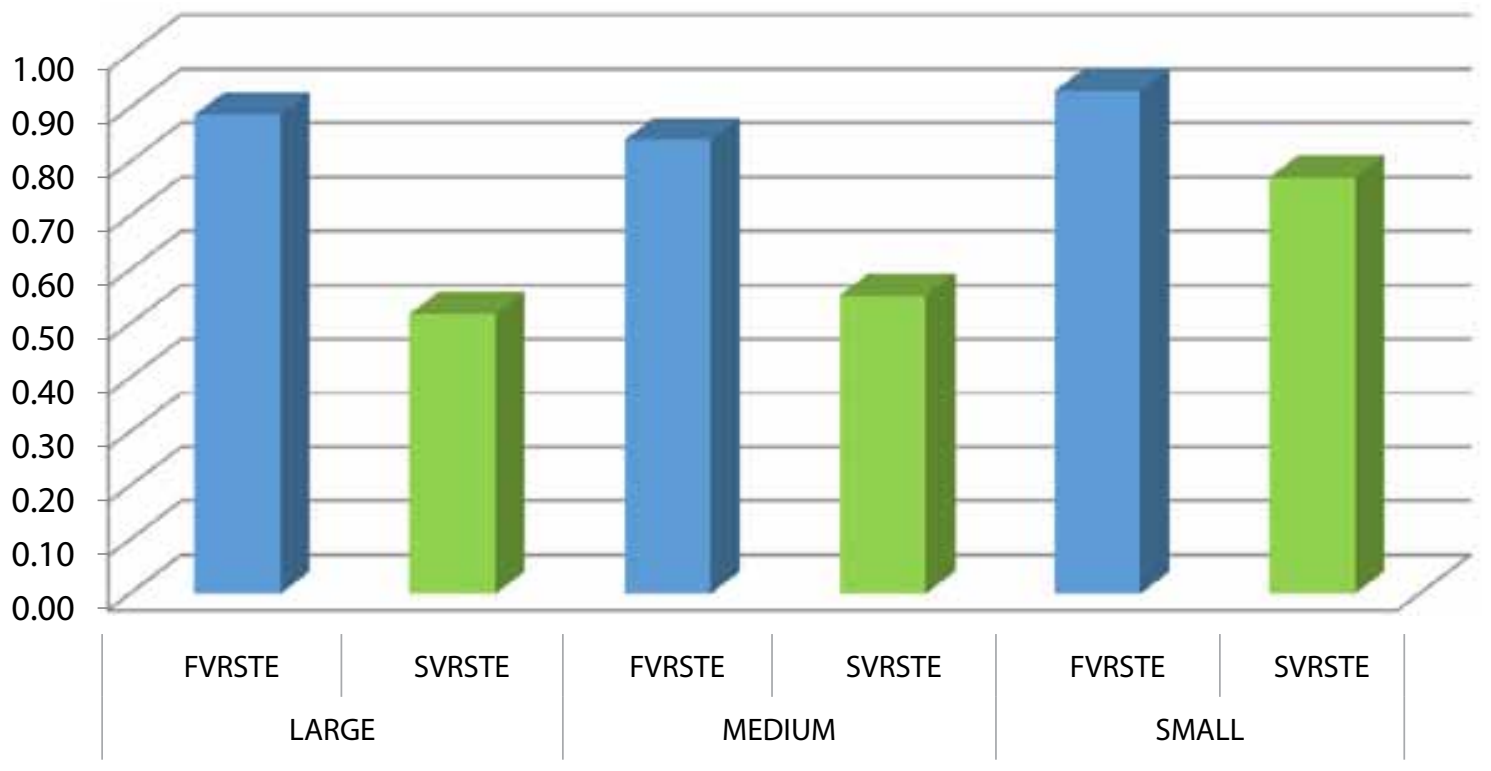


the purpose of our analysis we categorized MFIs into three groups based on total asset size, from small, medium to large scale ones, according to the following classification: small scale MFI, with total assets from 0-9.9 million BAM (S), medium scale, 10-99.9 million BAM (M), and large scale, from 99.9 million BAM (L). Accordingly, we check if different sized MFIs focus deferentially toward financial efficiency, or social contributions. We assumed that large-scale MFIs perform better in financial efficiency, while small and mediumsized MFls focus more on achieving higher levels of social efficiency than large ones.

When analyzing the DEA scores in relation to the total asset size of MFIs, in the case of large and medium sized MFIs both financial and social efficiency levels tend to be lower compared to small scale MFIs (Figure 2) ${ }^{3}$. This means that small-scale MFIs are more efficient in using their inputs. This could be due to the smaller number of clients they have and their capacity to assess each client individually and to take care of their needs, as well as to have a better system for monitoring their clients. However, while large scale MFIs focus more on economies of scale, as their assets grow, they focus more on fulfilling their financial goals. This means that, no matter larger they are in scale, large MFIs' relative outreach is smaller than those of small MFIs. In addition, for the analysis of the efficiency scores variations among the different sized MFIs, we adopted the Kruskal-Wallis rank test. Our results confirm a significant difference in the efficiency of differently sized MFIs (Table 9)

Table 9: Results for Kruskal-Wallis test on different sized MFIs

\begin{tabular}{|l|l|c|c|}
\hline Kruskal-Wallis Test & Size & N & Mean Rank \\
\hline \multirow{3}{*}{$\begin{array}{l}\text { Financial efficiency } \\
\text { (FVRSTE) }\end{array}$} & Small & 18 & 61.61 \\
\cline { 2 - 4 } & Medium & 41 & 34.83 \\
\cline { 2 - 4 } & Large & 29 & 47.55 \\
\cline { 2 - 4 } & Total & 88 & \\
\hline \multirow{3}{*}{$\begin{array}{l}\text { Social efficiency } \\
\text { (SVRSTE) }\end{array}$} & Small & 18 & 69.00 \\
\cline { 2 - 4 } & Medium & 41 & 42.24 \\
\cline { 2 - 4 } & Large & 29 & 32.48 \\
\cline { 2 - 4 } & Total & 88 & \\
\hline
\end{tabular}

From Table 9 it can be seen that the highest financial efficiency is present within small MFIs, which are followed by large ones in the case of financial

3 A more detailed results are available at request to the corresponding author Velid dr. Efendic: velid.efendic@efsa.unsa.ba efficiency, while for social efficiency medium sized MFIs are in second place. The lowest mean rank is within medium sized MFIs for financial efficiency, while on the contrary large MFIs have the lowest level of social efficiency.

Table 10: Test statistics of the Kruscal-Wallis test

\begin{tabular}{|l|c|c|}
\hline \multicolumn{3}{|c|}{ Test Statisticsa,b } \\
\hline & $\begin{array}{c}\text { Financial efficiency } \\
\text { (FVRSTE) }\end{array}$ & $\begin{array}{c}\text { Social efficiency } \\
\text { (SVRSTE) }\end{array}$ \\
\hline Chi-Square & 14.393 & 23.310 \\
\hline Df & 2 & 2 \\
\hline Asymp. Sig. & .001 & .000 \\
\hline \multicolumn{2}{|l|}{ a. Kruskal Wallis Test } \\
\hline \multicolumn{2}{|l|}{ b. Grouping Variable: Size } \\
\hline
\end{tabular}

Finally, we can conclude that our results confirm ( $p$ $=0.00$ for both efficiency scores) that there is a statistically significant difference in financial and social efficiency between the different sized MFIs. This means that a MFIs scale of operation is important for its efficiency. In addition, the management of each MFI has to take this into consideration when setting up their long-term strategy. For financial as well for social performance, the best scale of operations is up to $9.9 \mathrm{mil}$ BAM of assets, or within the category of small-sized MFIs. Accordingly, policy makers and governments that want to enhance the outreach of unbanked population in their environment should support small MFIs in their business, since their social sensitivity is higher compared to larger MFIs.

\subsection{Crisis effects on the two-dimensional efficiency of MFIs}

The literature on the effects of the global financial crisis showed that even though microfinance still has deep shock-resistant roots, it has become more linked to domestic and international financial markets, and thus the financial crisis is more likely to have a negative impact on its institutions (Littlefield and Kneiding 2009). Furthermore, Di Bella (2011) finds that links between microfinance and both international and domestic conditions are today much stronger than was previously believed and that MFIs are now more similar to traditional lending institutions. In our research, we assumed that during the crisis period, efficiency levels significantly decreased. We conducted a trend analysis of efficiency levels, which is presented in Figure 3. 
Figure 3: Financial and Social DEA scores-Overview for the analyzed period

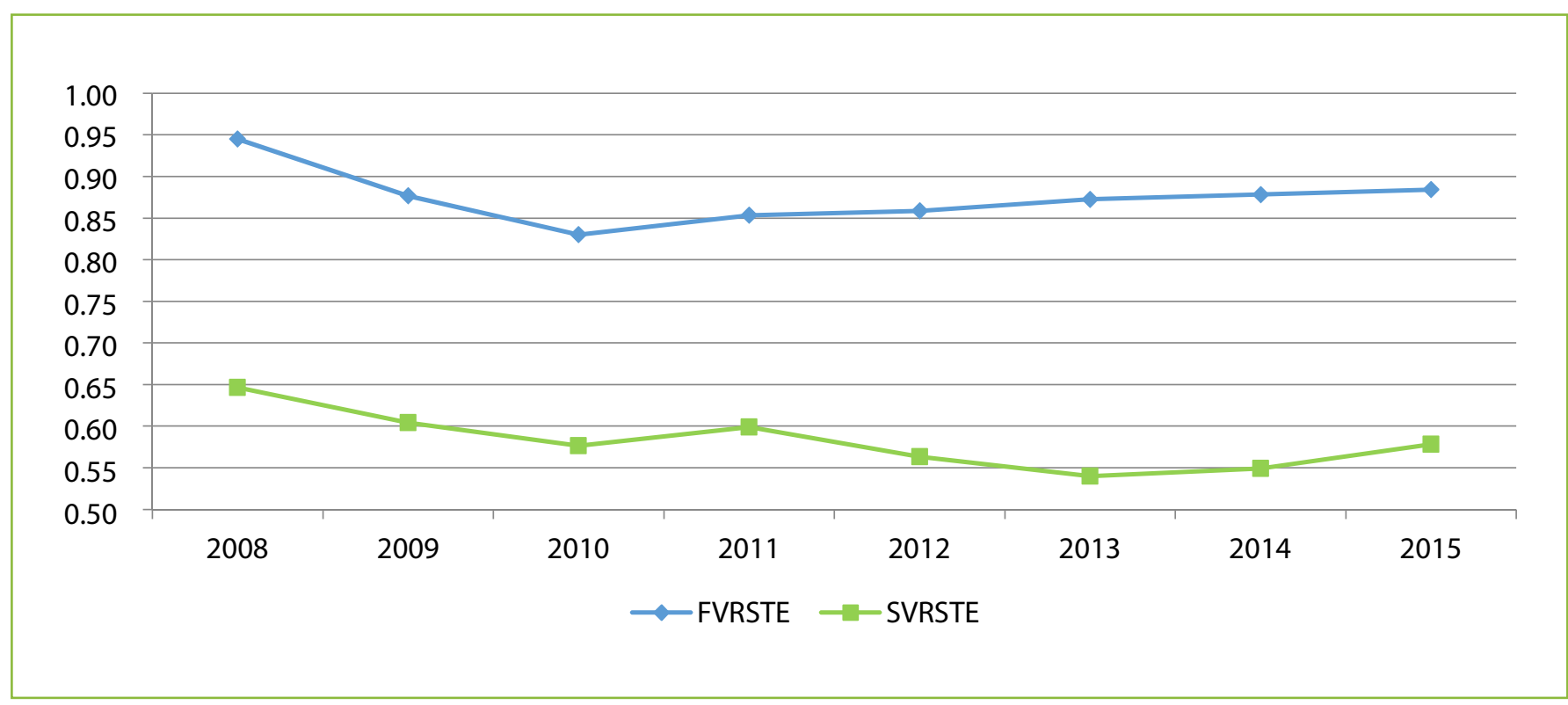

Figure 3 shows that the crisis had a higher negative effect on the financial rather than social efficiency of MFIs. The difference between financial and social efficiency decreased within the period 2010 to 2011. This leads us to the conclusion that MFIs retained their social role during the crisis. MFIs had the highest efficiency levels in the year 2008, which was the year leading up to the beginning of the financial crisis. The levels of both financial and social efficiency decreased up to 2010, when they reached their lowest values. This means that the crisis had a lagged effect in the period between 2008 and 2010. However, the financial efficiency score followed a positive trend from 2010, while social efficiency scores again decreased after 2011 and reached their lowest value in 2013. Accordingly, MFIs were more focused on financial efficiency in the after-crisis recovery period, which is in line with the aim of achieving sustainability. This is reasonable to expect, since sustainability goals are expected to be prioritized over social goals after the crisis recovery period.

It is also important to mention that the differences between financial and social efficiencies slightly decrease in the period from 2008 to 2011. This can be partially addressed by changes in loan policies. Before the crisis happened, MFIs were issuing a large number of loans without really considering their clients' indebtedness levels. Due to imperfect information about their indebtedness (a credit registry was introduced in 2008), clients were able to take a new loan in another MFI, regardless of the fact that they may be in late with the payments on their first loan. A survey of MFI clients conducted by Maurer and Pytkowska (2011) found that nearly $60 \%$ of borrowers had more than one outstanding microcredit debts, with a full $9 \%$ having more than five outstanding microcredit debts. When the crisis hit the market, many of the borrowers defaulted on their loans and both the level of NPLs and the PAR significantly increased. Hence, MFIs needed to introduce stricter credit policies so the number of borrowers significantly decreased, leaving a base of high quality clients. Since 2011, the market has shown signs of recovery, followed by a continuous increase in financial efficiency. At the same time, after a slight recovery in 2011, the level of social efficiency began to decrease through 2013, after which it once again began to show signs of a lagged recovery ${ }^{4}$.

Finally, we can conclude that although financial efficiency is higher than social efficiency, we have identified a suboptimal level for both efficiencies. In addition, differently sized MFIs have significantly different average efficiencies. Small MFIs are the most financially and socially efficient MFIs. The crisis had a negative effect on the efficiency of MFIs in $\mathrm{BiH}$, however the effect is significantly higher on financial rather than on social efficiency. After the crisis, the recovery proved to be slower for social efficiency, which suggests that MFIs prioritized financial goals over social goals in this period.

4 A more detailed results are available at request to the corresponding author Velid dr. Efendic: velid.efendic@efsa.unsa.ba 


\section{CONCLUSION}

In this paper, we investigate the "two dimensions" of social and financial efficiency of MFIs in BiH during and after the recent financial crisis. The results of the DEA analysis reveal that the average efficiencies of MFIs for both the financial and social efficiency are quite below optimal values: 0.87 and 0.59 , respectively. The correlation between these two is positive and statistically significant, suggesting that more financially efficient MFIs are more socially efficient as well. When assessing MFIs based on the differences in their total asset size, our results confirm that large and medium sized MFls have a lower level of both financial and social efficiency than smaller ones. Still, the differences are much more visible in the case of social efficiency in comparison to financial efficiency.

The study reveals that the crisis had a negative effect on both financial and social efficiency, while the difference between the two efficiencies slightly decreased within the period 2008 to 2011 . This leads us to the conclusion that MFIs retained their social role. However, after the crisis, the recovery showed the opposite, with financial efficiency prioritized over social efficiency, suggesting that MFIs were focused on their sustainability over their social purposes.

Finally, the results of this study suggest higher financial efficiency compared to social efficiency. However, we can conclude that although MFIs did not lose their social aims, their financial aims significantly over-perform social ones.

The small sample size is a significant limitation of this study. However, further research with a larger sample size consisting of international MFIs would be an improvement and would enable comparison between levels of efficiency and its determinants among different countries. Since the analysis of efficiency determinants is rarely assessed, it would be useful to expand this research and to analyze which determinants have direct influence on both social and financial efficiency.

\section{REFERENCES}

AnneWelle-Strand, Kjøllesdal, K. and Sitter, N. (2010). Assessing Microfinance: The Bosnia and Herzegovina Case. Managing Global Transitions, 8 (2), 145-166.

Anayiotos, G., Toroyan, H. and Vamvakidis, A. (2010). The Efficiency of Emerging Europea's Banking Sector Before and After Recent Economic Crisis, Financial Theory and Practice, 34 (3) 247-267.

Balkenhol, B. (2007). Efficiency and Sustainability in Microfinance. In B. Balkenhol (Ed.), Microfinance and
Public Policy: Outreach, Performance and Efficiency, 3-23, Basingstoke: Palgrave Macmillan.

Banker, R. D. and Natarajan, R. (2008). Evaluating Contextual Variables Affecting Productivity Using Data Envelopment Analysis. Operations Research, 56(1), 48-58. doi: 10.1287/ opre.1070.0460

Banker, R. D., Charnes, A. and Cooper, W. W. (1984). Some Models for Estimating Technical and Scale Inefficiencies in Data Envelopment Analysis. Management Science, 30(9), 1078-1092. doi: 10.1287/mnsc.30.9.1078

Bassem, B. S. (2008). Efficiency of Microfinance Institutions in the Mediterranean: An Application of DEA. Transition Studies Review, 15(2), 343-354. doi: 10.1007/ s11300-008-0012-7

Berryman, M. and Pytkowska, J. (2014). A Review of the Bosnian Microfinance Sector: Move to Financial SelfSufficiency. Microfinance Centre for Central and Eastern Europe and the New Independent States, and Microfinance information exchange.

Berger, A. N. and Humphrey, D. B. (1997). Efficiency of Financial Institutions: International Survey and Directions for Future Research. European Journal of Operational Research, 98,175-212.

Bogetoft, P. and Otto, L. (2010). Benchmarking with DEA, SFA, and R. New York, NY: Springer Science Business Media.

Casu, B. and Molyneux, P. (2003). A comparative study of efficiency in European banking. Applied Economics, 35(17), 1865-1876. doi: 10.1080/0003684032000158109

Charnes, A., Cooper, W. and Rhodes, E. (1979). Measuring the efficiency of decision-making units. European Journal of Operational Research, 3(4), 339. doi: 10.1016/0377-2217(79)90229-7

Chaves, R. A. and Gonzalez-Vega, C. (1996). The design of successful rural financial intermediaries: Evidence from Indonesia. World Development, 24(1), 65-78. doi10.1016/0305-750x (95)00114-r

Coelli, T. J., Rao, D. S. P., O'Donnell, C. J. and Batesse, G. E. (2005). An Introduction to Efficiency and Productivity Analysis (2nd ed.). New York: Springer Science Business Media.

Cook, W. D. and Seiford, L. M. (2009). Data envelopment analysis (DEA) - Thirty years on. European Journal of Operational Research, 192(1), 1-17. doi: 10.1016/j. ejor.2008.01.032

Cooper, W. W., Seiford, L. M. and Zhu, J. (2011). Handbook on data envelopment analysis. Boston: Springer

Cooper, W. W., Tone, K. and Seiford, L. M. (2006). Introduction to Data Envelopment Analysis and Its Uses: With DEASolver Software and References. Boston: Springer.

Cull, R., Demirguc-Kunt, A. and Morduch, J. (2009). "Microfinance Meets the Market." Journal of Economic Perspectives, 23(1): 167-92. doi: 10.1257/jep.23.1.167 
Di Bella, G. (2011). The Impact of the Global Financial Crisis on Microfinance and Policy Implications, IMF WP No. 11/175, IMF

Efendic,V. (2014). Efikasnost banaka u Jugoistocnoj Evropi s posebnim osvrtom na Bosnu i Hercegovinu. Sarajevo: Ekonomski fakultet Sarajevo.

Efendic, V. and Hadzic, F. (2017). Business Model and Operational Efficiency of Microfinance in Bosnia and Herzegovina: Lessons for Islamic Microfinance, Chapter 9th, Critical Issues and Challenges in Islamic Economics and Finance Development. Palgrave Macmillan. 191-211.

Emrouznejad, A. and Yang, G. (2017). A survey and analysis of the first 40 years of scholarly literature in DEA: 1978-2016. Socio-Economic Planning Sciences, 1-5. doi: 10.1016/j.seps.2017.01.008

Ernst\&Young. (2014). Challenges in Microfinance: and EY perspective. EY.

Evanoff, D. D. and Israilevich, P. R., (1991). Productive efficiency in banking. Economic Perspectives(Federal Reserve Bank of Chicago), 11-32.

Fanchon, P. (2003). Variable selection for dynamic measures of efficiency in the computer industry. International Advances in Economic Research, 9(3), 175-188. doi: 10.1007/bf02295441

Flückiger, Y. and Vassiliev, A. (2007). Efficiency in Microfinance Institutions: An Application of Data Envelopment Analysis to MFIs in Peru. Microfinance and Public Policy, 89-110. doi: 10.1057/97802303000266

Grigorian, D. A. and Manole, V. (2006). Determinants of Commercial Bank Performance in Transition: An Application of Data Envelopment Analysis. Comparative Economic Studies, 48(3), 497-522. doi: 10.1057/palgrave. ces.8100129

Gutiérrez-Nieto, B., Serrano-Cinca, C. and Molinero, C. M. (2007). Microfinance institutions and efficiency. Omega, 35(2), 131-142. doi: 10.1016/j.omega.2005.04.001

Haq, M., Skully, M. and Pathan, S. (2009). Efficiency of Microfinance Institutions: A Data Envelopment Analysis. Asia-Pacific Financial Markets, 17(1), 63-97. doi: 10.1007/ s10690-009-9103-7

Hassan, K. M. and Sanchez, B. (2009). Efficiency Analysis of Microfinance Institutions in Developing Countries. SSRN Electronic Journal. doi: 10.2139/ssrn.1492238

Hassan, M. K. and Tufte, D. R. (2001). The X-Efficiency of a Group-Based Lending Institution: The Case of the Grameen Bank. World Development, 29(6), 1071-1082. doi: 10.1016/s0305-750x(01)00014-6

Hassan, M. K., Sanchez, B. and Ngene, G. (2012). SCALEs and technical efficiencies in Middle East and North African (MENA) micro financial institutions. International Journal of Islamic and Middle Eastern Finance and Management, 5(2), 157-170. doi: 10.1108/17538391211233434

Jenkins, L. and Anderson, M. (2003). A multivariate statistical approach to reducing the number of variables in data envelopment analysis. European Journal of Operational Research, 147(1), 51-61. doi: 10.1016/ s0377-2217(02)00243-6

Kipesha, E. (2012). Efficiency of Microfinance Institution in East Africa: DEA. European Journal of Business and Management, 4(17) 77-88.

Krauss, A., Meyer, J. and Pytkowska, J. (2013). The Level of Indebtedness of MSME Credit Customers and Quality of Finance in Bosnia and Herzegovina. Retrieved from Microfinance Gateway:http://www.mfc.org.pl/sites/mfc. org.pl/files/efse_df_indebtedness_study_2013_in_bih_ summary_paper.pdf. 30.07.2016.

Lebovics, M., Hermes, N. and Hudon, M. (2016). Are Financial and Social Efficiency Mutually Exclusive? A Case Study of Vietnamese Microfinance Institutions. Annals of Public and Cooperative Economics, 87(1), 55-77. doi: 10.1111/ apce. 12085

Lindh de Montoya, M. and McNeil, J. (2003). Microcredit Organizations and Savings Mobilization in Bosnia and Herzegovina. FSBAT assessment for USAID.

Littlefield, E. and Kneiding, C. (2009). The Global Financial Crisis and Its Impact on Microfinance. CGAP.

Mester, L. J. (1996). A study of bank efficiency taking into accountrisk-preferences.Journal ofBanking\&Finance,20(6), 1025-1045. doi: 10.1016/0378-4266(95)00047-x

MFC (Microfinance Center) (2008). Access of Low Income Households to Financial Services in $\mathrm{BiH}$. Microfinance Center.

Milford, B., Sinkovic, D. and Skare, M. (2012). The contribution of the microfinance model to Bosnia's post-war reconstruction and development: how to destroy and economy and society without really trying. Austrian Foundation for Development Research (Ofse), 36

MIX Market, AMFI. (2009). Bosnia and Herzegovina Microfinance Analysis and Benchmarking Report 2008. Retrieved from THE MIX: https://www.themix. org/sites/default/files/publications/Bosnia\%20and\%20 Herzegovina\%20Microfinance\%20Analysis\%20and\%20 Benchmarking\%20Report\%202008_0.pdf. 29.07.2016.

Mohd Tahir, I. and Nurzahira Che Tahrim, S. (2013). Efficiency Analysis of Microfinance Institutions in ASEAN: A DEA Approach. Business Management Dynamics, 3(4), 13-23.

Morduch, J. (2000). The Microfinance Schism. World Development, 28(4), 617-629. doi: 10.1016/ s0305-750x(99)00151-5

Parkin, M. (2012). Microeconomics (10th ed.) Pearson Education.

Pedraja-Chaparro, F., Salinas-Jimenez, J. and Smith, P. (1999). On the Quality of the Data Envelopment Analysis Model. The Journal of the Operational Research Society, 50(6), 636-644. doi: 10.2307/3010620

Ramanathan, R. (2003). An Introduction to data envelopment analysis: A tool for performance measurement. SAGE Publications, New Delhi. 
Schmidt, P. and Sickles, R. C. (1984). Production Frontiers and Panel Data. Journal of Business \& Economic Statistics, 2(4), 367-374. doi: 10.1080/07350015.1984.10509410

Sedzro, K. and Keita, M. (2009) Assessing the Efficiency of Microfinance Institutions Using Data Envelopment Analysis. Journal of International Finance \& Economics, 9, 54-67.

Seiford, M. L., Tone, K. and Cooper, W. W. (2007). Data Envelopment Analysis: A Comprehensive Text with Models, Applications, Referenced and DEA-Solver Software. Springer.

Serrano-Cinca, C., Gutiérrez-Nieto, B. and Molinero, C. M. (2009). Social Efficiency in Microfinance Institutions. Journal of The Operational Research Society, 60 (19), 104-119

Tucker, M. (2001). Financial performance of selected Microfinance institutions. Journal of Microfinance, 3(2), 107-123.

World Bank (2012). Diagnostic Review of Consumer Protection in the Microfinance Sector. World Bank Resources.

World Bank (2005). Retrieved from WB Site sources: http://siteresources.worldbank.org/INTBOSNIAHERZ/Resources/ LIP2.pdf 14.06.2016.
WB Resources. (2001). Innovative Approaches to Microfinance in Post-Conflict Situations: Bosnia Local Initiatives Project. Retrieved from Site Resources WB: http://siteresources.worldbank.org/INTRANETSOCIAL DEVELOPMENT/873351-1111664103368/20489583/ sdn50-Bosnia.pdf. 24.06.2016.

Widiarto, I. and Emrouznejad, A. (2015). Social and financial efficiency of Islamic microfinance institutions: A Data Envelopment Analysis application. SocioEconomic Planning Sciences, 50, 1-17. doi: 10.1016/j. seps.2014.12.001

Wijesiri, M., Viganò, L. and Meoli, M. (2015). Efficiency of microfinance institutions in Sri Lanka: a two-stage double bootstrap DEA approach. Economic Modelling, 47, 7483. doi: 10.1016/j.econmod.2015.02.016

Yaron, J. (1994). What Makes Rural Finance Institutions Successful? The World Bank Research Observer, 9(1), 4970. doi: 10.1093/wbro/9.1.49

Zeller, M., Sharma, M., Henry, C. and Lapenu, C. (2006). An operational method for assessing the poverty outreach performance of development policies and projects: Results of case studies in Africa, Asia, and Latin America. World Development, 34(3), 446-464. doi: 10.1016/j. worlddev.2005.07.020 


\section{APPENDICES}

Appendix 1: Input/Output Variables

\begin{tabular}{|c|c|c|c|}
\hline Inputs & Definition & Link with Literature & Units \\
\hline Noemploy - Employees & $\begin{array}{l}\text { The number of individuals who are actively } \\
\text { employed by an MFI. This number includes } \\
\text { contract employees or advisors who dedi- } \\
\text { cate the majority of their time to the MFI }\end{array}$ & $\begin{array}{l}\text { Bassem(2008), Hassan and } \\
\text { Sanchez (2009), Sedzro and } \\
\text { Keita (2009), Kipesha (2012), } \\
\text { and Haq et al. (2010) }\end{array}$ & Numeric \\
\hline Totass- Total assets & Total of all net asset accounts. & $\begin{array}{l}\text { Widiarto and Emouznejad } \\
\text { (2015), Wijesiri et al. (2015), } \\
\text { Tahir (2013), Kipesha (2012), } \\
\text { Gutiérrez-Nieto et al. (2009), } \\
\text { Hassan and Sanchez (2009), } \\
\text { Bassem (2008) }\end{array}$ & BAM '000 \\
\hline Outputs & Definition & Usage in Literature & Units \\
\hline
\end{tabular}

\begin{tabular}{|c|c|c|c|}
\hline $\begin{array}{l}\text { Finrev - Financial } \\
\text { Revenue }\end{array}$ & $\begin{array}{l}\text { Revenue from loan portfolio. It is used as } \\
\text { an output in the production approach and } \\
\text { a proxy for sustainability since an MFI that } \\
\text { cannot collect enough revenue will not be } \\
\text { viable to operate in the long run by itself }\end{array}$ & $\begin{array}{l}\text { Gutiérrez-Nieto et al. (2009) and } \\
\text { Hassan and Sanchez (2009). }\end{array}$ & BAM '000 \\
\hline $\begin{array}{l}\text { Groloan - Gross Loan } \\
\text { Portfolio }\end{array}$ & $\begin{array}{l}\text { The outstanding principal balance of all } \\
\text { of an MFI's outstanding loans, including } \\
\text { current, delinquent, and restructured loans, } \\
\text { but not loans that have been written off. It } \\
\text { does not include interest receivable }\end{array}$ & $\begin{array}{l}\text { Kipesha (2012), } \\
\text { Hassan et al. (2012), } \\
\text { Gutiérrez-Nieto et al. (2009) }\end{array}$ & BAM '000 \\
\hline
\end{tabular}

Noborow - Number of Active Borrowers (Social output)
The number of individuals who currently have an outstanding loan balance with the MFI or are primarily responsible for repaying any portion of the gross loan portfolio. Herein, it is used as an output to resemble the breadth of outreach.
Widiarto and Emrouznejad (2015), Numeric

Source: MIX Market Glossary and (Widiarto and Emrouznejad, 2015), with authors updates 
Appendix 2: Correlation of the inputs and outputs used

\begin{tabular}{|l|c|c|c|c|c|}
\hline $\begin{array}{l}\text { Spearman's rho } \\
(\mathrm{N}=88)\end{array}$ & Groloan & Finrev & Noborow & Totas & Noemploy \\
\hline Groloan & 1.00 & $0.95^{* *}$ & $0.96^{* *}$ & $0.99^{* *}$ & $0.95^{* *}$ \\
\hline Finrev & $0.95^{* *}$ & 1.00 & $0.93^{* *}$ & $0.95^{* *}$ & $0.94^{* *}$ \\
\hline Noborow & $0.96^{* *}$ & $0.93^{* *}$ & 1.00 & $0.96^{* *}$ & $0.95^{* *}$ \\
\hline Totass & $0.99^{* *}$ & $0.95^{* *}$ & $0.96^{* *}$ & 1.00 & $0.96^{* *}$ \\
\hline Noemploy & $0.95^{* *}$ & $0.94^{* *}$ & $0.95^{* *}$ & $0.96^{* *}$ & 1.00 \\
\hline
\end{tabular}

**. Correlation is significant at the 0.01 level (2-tailed).

Appendix 3: Spearman's Rho correlation of the social and financial efficiency scores for all models

\begin{tabular}{|c|c|c|c|c|c|c|c|c|c|}
\hline $\begin{array}{l}\text { Spearman's } \\
\text { rho }(\mathrm{N}=88)\end{array}$ & FCRSTE & FVRSTE & FSCALE & SCRSTE & SVRSTE & SSCALE & FCRSTE2 & FVRSTE2 & FSCALE2 \\
\hline FCRSTE & 1.0 & $0.97^{* *}$ & $0.21 *$ & $0.23 *$ & $0.26^{*}$ & 0.01 & $0.94^{* *}$ & $0.91^{* *}$ & 0.20 \\
\hline FVRSTE & $0.97^{* *}$ & 1.00 & 0.04 & $0.27^{*}$ & $0.29^{* *}$ & -0.01 & $0.91^{* *}$ & $0.94^{* *}$ & 0.03 \\
\hline FSCALE & $0.21^{*}$ & 0.04 & 1.00 & 0.04 & 0.07 & -0.01 & 0.14 & 0.00 & $0.91^{* *}$ \\
\hline SCRSTE & $0.23^{*}$ & $0.27^{*}$ & 0.04 & 1.00 & $0.97^{* *}$ & $-0.21^{*}$ & $0.23^{*}$ & $0.28^{* *}$ & -0.01 \\
\hline SVRSTE & $0.26^{*}$ & $0.29^{* *}$ & 0.07 & $0.97^{* *}$ & 1.00 & $-0.37^{* *}$ & $0.24^{*}$ & $0.29^{* *}$ & 0.01 \\
\hline SSCALE & 0.01 & -0.01 & -0.01 & $-0.21^{*}$ & $-0.37^{* *}$ & 1.00 & 0.08 & 0.03 & 0.10 \\
\hline FCRSTE2 & $0.94^{* *}$ & $0.91^{* *}$ & 0.14 & $0.23^{*}$ & $0.24^{*}$ & 0.08 & 1.00 & $0.97^{* *}$ & $0.23^{*}$ \\
\hline FVRSTE2 & $0.91^{* *}$ & $0.94^{* *}$ & 0.00 & $0.28^{* *}$ & $0.29^{* *}$ & 0.03 & $0.97^{* *}$ & 1.00 & 0.08 \\
\hline FSCALE2 & 0.20 & 0.03 & $0.91^{* *}$ & -0.01 & 0.01 & 0.10 & $0.23^{*}$ & 0.08 & 1.00 \\
\hline
\end{tabular}

**. Correlation is significant at the 0.01 level (2-tailed).

Appendix 4: Descriptive statistics DEA results - all models

\begin{tabular}{|c|c|c|c|c|c|}
\hline \multicolumn{6}{|c|}{ Descriptive Statistics DEA results - all models } \\
\hline Variable & Obs & Mean & Std. Dev. & Min & Max \\
\hline \multicolumn{6}{|c|}{ Main model - Financial efficiency } \\
\hline FCRSTE & 88 & 0.86 & 0.08 & 0.59 & 1 \\
\hline FVRSTE & 88 & 0.87 & 0.09 & 0.60 & 1 \\
\hline FSCALE & 88 & 0.98 & 0.02 & 0.87 & 1 \\
\hline \multicolumn{6}{|c|}{ Main model - Social efficiency } \\
\hline SCRSTE & 88 & 0.55 & 0.15 & 0.37 & 1 \\
\hline SVRSTE & 88 & 0.59 & 0.18 & 0.39 & 1 \\
\hline SSCALE & 88 & 0.96 & 0.06 & 0.67 & 1 \\
\hline \multicolumn{6}{|c|}{ Financial efficiency 2} \\
\hline FCRSTE2 & 88 & 0.85 & 0.08 & 0.59 & 1 \\
\hline FVRSTE2 & 88 & 0.87 & 0.09 & 0.60 & 1 \\
\hline FSCALE2 & 88 & 0.98 & 0.02 & 0.87 & 1 \\
\hline
\end{tabular}

CRSTE- constant return to SCALE technical efficiency (TE); VRSTE - variable return to scale TE, SCALE - scale efficiency; Fstands for financial, S- stands for social dimension 